\title{
The Safety of Laryngeal Mask Airway-Assisted Bronchoscopy versus Standard Nasal Bronchoscopy
}

\author{
Daniel Alon a, c Barak Pertzov b, c Evgeni Gershman ${ }^{b, c}$ Miryam Frishman ${ }^{a, c}$ \\ Nader Abdel Rahman ${ }^{\text {b, c }}$ Dror Rosengarten ${ }^{\text {b, c }}$ Mordechai R. Kramer ${ }^{\text {b, c }}$ \\ ${ }^{a}$ Department of Anesthesia and ${ }^{\mathrm{b}}$ The Pulmonary Division, Rabin Medical Center, Petach Tikva, and \\ 'Sackler Faculty of Medicine, Tel Aviv University, Tel Aviv, Israel
}

\section{Keywords}

Laryngeal mask · Bronchoscopy - Oxygen saturation . Cutaneous carbon dioxide tension - Blood pressure .

Sedation

\begin{abstract}
Background: The use of laryngeal mask airway (LMA) for fiberoptic bronchoscopy was first described in 1982. The LMA was found to be beneficial in operator view, flexibility, and also in maintaining stable oxygen saturation. Despite its advantages, the use of LMA has not become widespread. $\mathbf{O b}$ jective: The aim of this paper was to evaluate the safety of LMA-assisted bronchoscopy compared to standard nasal bronchoscopy. Methods: We conducted a prospective randomized trial. The study group included 105 patients prospectively randomized to undergo either LMA-assisted (53 patients) or standard nasal bronchoscopy (52 patients). The data collected included continuous monitoring of respiratory and hemodynamic parameters and medication doses. Results: The LMA group had a significantly lower percentage
\end{abstract}

(c) 2017 S. Karger AG, Basel

E-Mail karger@karger.com www.karger.com/res of desaturation (pulse oximetry saturation $\left[\mathrm{SpO}_{2}\right]<88 \%$ ) events compared to the non-LMA (NLMA) group (37 vs. $63.4 \% ; p=0.008)$. The median percentage of time with $\mathrm{SpO}_{2}$ $>88 \%$, from the total procedure time, was $100 \%$ (IQR 98-100) in the LMA group and 98\% (IQR 96-98) in the NLMA group $(p=0.003)$. Sedation in the LMA group required significantly higher doses of propofol $(p<0.001)$. The mean systolic blood pressure values were significantly lower in the LMA group, but this difference did not result in a higher percentage of clinically significant hypotension. Conclusion: The use of LMA allows for better airway support, stable oxygen saturation, and a more convenient port of entry during flexible fiberoptic bronchoscopy. These results, together with the known advantages of the laryngeal mask, should lead to more widespread use in the evolving field of interventional pulmonology, in particular in high-risk patients and complicated procedures.

(c) 2017 S. Karger AG, Basel

D.A. and B.P. contributed equally to this work.

Mordechai R. Kramer, MD 


\section{Introduction}

Fiberoptic bronchoscopy is commonly used for the diagnosis and management of a variety of lung diseases [1, $2]$. Desaturation during the procedure is common and requires saturation monitoring and, when needed, oxygen supplementation [3,4]. Older age, comorbidities, type and severity of the baseline chronic lung disease, and the type of procedure all influence the frequency and severity of desaturation [5-8]. Stable airway control may be achieved with the use of an endotracheal tube, and while this option is used in high-risk or already intubated patients, it is not practical for ambulatory and stable, hospitalized patients. Therefore, a simpler and less invasive solution is needed for a better airway support during bronchoscopy.

The laryngeal mask airway (LMA), first presented in 1983 , had a profound impact on airway management $[8$, 9]. The use of LMA for airway management during flexible fiberoptic bronchoscopy (FFB) was first introduced in 1989 and since then has been described as a safe and convenient tool for airway control during bronchoscopy in both adult and pediatric populations [10-13]. Its advantage compared to the endotracheal tube is the use of a larger diameter conduit, allowing a better view and flexibility $[14,15]$.

LMA has been successfully used in some specific FFB procedures, such as balloon dilation, brachytherapy, bronchial stenting, and foreign body extraction [16-18].

Notwithstanding its advantages over nasal bronchoscopy, LMA has not been widely used, and to our knowledge, no study has compared the use of LMA-assisted bronchoscopy to standard nasal bronchoscopy. In this study, we sought to evaluate the use of LMA during FFB by monitoring the hemodynamics, pulse oxygen saturation $\left(\mathrm{SpO}_{2}\right)$, transcutaneous $\mathrm{PCO}_{2}$, and complications.

\section{Methods}

A prospective randomized study was conducted at a tertiary medical center from February to September 2016. The study group included 105 patients scheduled for FFB under local anesthesia with sedation.

Inclusion criteria were age $>18$ years, $\mathrm{SpO}_{2}>95 \%$ in room air, and hemodynamic stability at the beginning of the procedure. We included both ambulatory and hospitalized patients. All subjects provided written informed consent for bronchoscopy, and the study has been approved by the local ethics committee (ClinicalTrials.gov, identifier: NCT02698007). Exclusion criteria for the study were inability or refusal to provide informed consent, bronchoscopy through an artificial airway, such as endotracheal tube or tracheostomy. Alternating patient randomization was used to assign each patient to either LMA or nasal bronchoscopy. An anesthesiologist was present throughout each procedure and was in charge of monitoring the patients and the sedation protocol that was identical in all patients and included administration of fentanyl (50-100 $\mu \mathrm{g})$, midazolam (1-5 mg), and propofol according to the procedure length. The bronchoscope was inserted through a swivel adapter, and visual confirmation was done by the performing pulmonologist. The LMA was connected to a self-inflating resuscitation bag (Ambu with oxygen reservoir) that was used according to the anesthesiologist discretion.

In all cases, monitoring included continuous electrocardiography, pulse oximetry, transcutaneous $\mathrm{PCO}_{2}$, and automated noninvasive blood pressure recordings every $5 \mathrm{~min}$. All patients received supplemental nasal oxygen at $2-5 \mathrm{~L} / \mathrm{min}$. The duration of bronchoscopy was calculated from the administration of sedation until the flexible bronchoscope was removed from the tracheobronchial tree.

\section{Study Outcomes}

The primary outcome was any event of desaturation $<88 \%$ and was obtained with constant pulse oximetry monitoring. We also evaluated the percentage of procedure time with $\mathrm{SpO}_{2}>88 \%$. Secondary outcomes were a cutaneous carbon dioxide tension $\left(\mathrm{PcCO}_{2}\right)$ rise $>55 \mathrm{~mm} \mathrm{Hg}, \mathrm{SpO}_{2}$ and $\mathrm{PcCO}_{2}$ levels, blood pressure, doses of drugs used for sedation, and complications.

\section{Statistical Analysis}

The baseline characteristics and secondary outcomes were compared with the Student $t$ test, $\chi^{2}$ test, and the Mann-Whitney $\mathrm{U}$ test, as appropriate. The primary outcome was analyzed as a dichotomous variable with the $\chi^{2}$ test and also as percentage of the procedure time with $\mathrm{SpO}_{2}>88 \%$ with the Mann-Whitney U test.

\section{Results}

The LMA group consisted of 53 patients, and the nonLMA (NLMA) group consisted of 52 patients. Table 1 shows the background and clinical characteristics of the 2 groups. There were no significant between-group differences in demographics, type of procedure, and baseline hemodynamic and respiratory parameters. The LMA group had a higher percentage of male patients and a longer procedure time, but these differences were not significant.

\section{Primary Outcome}

Overall the LMA group had 20 (37\%) patients with a drop of $\mathrm{SpO}_{2}<88 \%$ at any time during the procedure in comparison to $33(63.4 \%)$ patients in the NLMA group $(p=0.008)$. The median percentage of time with $\mathrm{SpO}_{2}$ $>88 \%$, from the total procedure time, was $100 \%$ (interquartile range [IQR] 98-100) in the LMA group and $98 \%$ (IQR 96-98) in the NLMA group $(p=0.003)$. Table 2 and 
Table 1. Background and clinical characteristics of 109 patients undergoing bronchoscopy

\begin{tabular}{|c|c|c|c|c|}
\hline & All patients & LMA group & NLMA group & $p$ value \\
\hline Patients & 105 & 53 & 52 & \\
\hline Age, years & $62.3 \pm 14.23$ & $62.05 \pm 14.46$ & $62.67 \pm 14.13$ & 0.82 \\
\hline Males/females & $62 / 43$ & $36 / 17$ & $26 / 26$ & 0.06 \\
\hline BMI & $25.1 \pm 5.4$ & $25.37 \pm 5.21$ & $24.92 \pm 5.8$ & 0.46 \\
\hline \multicolumn{5}{|l|}{ Comorbidities } \\
\hline HTN & $34(32.4)$ & $16(30.2)$ & $18(34.6)$ & 0.62 \\
\hline IHD & $15(14.3)$ & $8(15.1)$ & $7(13.5)$ & 0.81 \\
\hline Asthma & $1(1)$ & 0 & $1(1.9)$ & 0.49 \\
\hline COPD & $23(21.9)$ & $13(24.5)$ & $10(19.2)$ & 0.51 \\
\hline Smoker & $21(20)$ & $10(18.9)$ & $11(21.2)$ & 0.77 \\
\hline Lung malignancy & $30(28.6)$ & $17(32.1)$ & $13(25.0)$ & 0.42 \\
\hline Lung transplantation & $21(20)$ & $13(24.5)$ & $8(15.4)$ & 0.26 \\
\hline Two or more comorbidities & $25(22.9)$ & $14(24.6)$ & $11(21.2)$ & 0.67 \\
\hline \multicolumn{5}{|l|}{ Procedure } \\
\hline Bronchoalveolar lavage & 105 & 53 & 52 & \\
\hline Transbronchial biopsy & 39 & 23 & 16 & \\
\hline Cryobiopsy & 29 & 17 & 12 & \\
\hline Endobronchial biopsy & 23 & 10 & 13 & \\
\hline Mechanical dilatation & 11 & 3 & 8 & \\
\hline Laser & 10 & 4 & 6 & \\
\hline Bronchial brushings & 8 & 5 & 3 & \\
\hline EBUS & 4 & 4 & 0 & \\
\hline Brachytherapy & 1 & 1 & 0 & \\
\hline Bronchography & 2 & 1 & 1 & \\
\hline Stent placement & 2 & 1 & 1 & \\
\hline \multicolumn{5}{|l|}{ Baseline parameters } \\
\hline $\mathrm{PcCO}_{2}, \mathrm{~mm} \mathrm{Hg}$ & $38.34 \pm 6.36$ & $38.84 \pm 7.22$ & $37.84 \pm 5.38$ & 0.44 \\
\hline $\mathrm{SpO}_{2}, \%$ & $98.58 \pm 2.07$ & $98.31 \pm 2.34$ & $98.88 \pm 1.69$ & 0.37 \\
\hline $\mathrm{SBP}, \mathrm{mm} \mathrm{Hg}$ & $135.63 \pm 18.98$ & $133.75 \pm 19.02$ & $137.54 \pm 18.93$ & 0.31 \\
\hline $\mathrm{DBP}, \mathrm{mm} \mathrm{Hg}$ & $76.92 \pm 16.24$ & $78.46 \pm 11.34$ & $75.38 \pm 19.98$ & 0.33 \\
\hline $\mathrm{HR}, \mathrm{bpm}$ & $77.38 \pm 16.47$ & $77.26 \pm 18.34$ & $77.5 \pm 14.51$ & 0.94 \\
\hline
\end{tabular}

Values are presented as $n, n(\%)$, or mean \pm standard deviation. LMA, laryngeal mask airway; NLMA, nonLMA; BMI, body mass index; HTN, hypertension; IHD, ischemic heart disease; COPD, chronic obstructive pulmonary disease; EBUS, endobronchial ultrasound; $\mathrm{PCCO}_{2}$, cutaneous carbon dioxide tension; $\mathrm{SpO} 2$, pulse oximetry saturation; SBP, systolic blood pressure; DBP, diastolic blood pressure; HR, heart rate.

Table 2. Cardinal hemodynamic, respiratory, and medication monitoring during the procedure

\begin{tabular}{lccc}
\hline & LMA & NLMA & $p$ value \\
\hline $\mathrm{SpO}_{2}<88 \%$ & $20 / 53$ & $33 / 52$ & 0.008 \\
$\mathrm{SpO}_{2}>88 \%$ (percentage from procedure time) & $100 ; 98-100$ & $98 ; 96-100$ & 0.003 \\
$\mathrm{PcCo}_{2}>55 \mathrm{~mm} / \mathrm{Hg}$ & $30 / 47$ & $28 / 48$ & 0.58 \\
$\mathrm{SBP}<90 \mathrm{~mm} \mathrm{Hg}$ & $7 / 52$ & $7 / 53$ & 0.96 \\
Propofol dosage, mg & $200 ; 165-300$ & $120 ; 70-200$ & $<0.001$ \\
Midazolam dosage, $\mathrm{mg}$ & $1 ; 1-1$ & $1 ; 1-3$ & 0.21 \\
Fentanyl dosage, $\mu \mathrm{g}$ & $100 ; 100-100$ & $100 ; 100-100$ & 0.07 \\
Duration of procedure, min & $20 ; 15-27.5$ & $20 ; 15-25$ & 0.055 \\
\hline
\end{tabular}

Values are presented as $n$ or median; interquartile range. LMA, laryngeal mask airway; NLMA, non-LMA; $\mathrm{SpO}_{2}$, pulse oximetry saturation; $\mathrm{PcCO}_{2}$, cutaneous carbon dioxide tension; SBP, systolic blood pressure. 
Table 3. Monitoring of $\mathrm{SpO}_{2}, \mathrm{PcCO}_{2}$, heart rate, and systolic blood pressure during bronchoscopy

\begin{tabular}{|c|c|c|c|c|c|c|c|c|c|c|c|c|c|c|}
\hline \multirow{2}{*}{$\begin{array}{l}\text { Time, } \\
\text { min }\end{array}$} & \multicolumn{5}{|c|}{ LMA } & \multicolumn{5}{|c|}{ NLMA } & \multicolumn{4}{|l|}{$p$ value } \\
\hline & $n$ & $\begin{array}{l}\mathrm{SpO}_{2}, \% \\
\text { (median; } \\
\mathrm{IQR} \text { ) }\end{array}$ & $\begin{array}{l}\mathrm{PcCO}_{2} \\
\mathrm{~mm} \mathrm{Hg} \\
(\text { mean } \pm \mathrm{SD})\end{array}$ & $\begin{array}{l}\mathrm{HR} \\
(\text { mean } \pm \mathrm{SD})\end{array}$ & SBP, mm Hg & $n$ & $\begin{array}{l}\mathrm{SpO}_{2}, \% \\
\text { (median; } \\
\mathrm{IQR} \text { ) }\end{array}$ & $\begin{array}{l}\mathrm{PcCO}_{2} \\
\text { mm Hg } \\
(\text { mean } \pm \mathrm{SD})\end{array}$ & $\begin{array}{l}\mathrm{HR} \\
(\text { mean } \pm \mathrm{SD})\end{array}$ & $\mathrm{SBP}, \mathrm{mm} \mathrm{Hg}$ & $\begin{array}{l}\mathrm{SpO}_{2} \\
\%\end{array}$ & $\begin{array}{l}\mathrm{PcCO}_{2} \\
\mathrm{~mm} \mathrm{Hg}\end{array}$ & HR & $\begin{array}{l}\text { SBP, } \\
\mathrm{mm} \mathrm{Hg}\end{array}$ \\
\hline 5 & 53 & $\begin{array}{l}99 \\
96-100\end{array}$ & $44.73 \pm 8.3$ & $81.07 \pm 18.36$ & $125.3 \pm 21.2$ & 52 & $\begin{array}{l}99 \\
90-100\end{array}$ & $44.5 \pm 7.84$ & $80.48 \pm 14.79$ & $134.88 \pm 22.58$ & 0.44 & 0.88 & 0.85 & 0.02 \\
\hline 10 & 53 & $\begin{array}{l}100 \\
97-100\end{array}$ & $50.91 \pm 9.23$ & $80.69 \pm 15.44$ & $114.77 \pm 22.35$ & 52 & $\begin{array}{l}96 \\
90-99\end{array}$ & $51.02 \pm 10.43$ & $85.76 \pm 18.37$ & $25.51 \pm 3.57$ & $<0.001$ & 0.95 & 0.12 & $<0.001$ \\
\hline 15 & 52 & $\begin{array}{l}100 \\
98-100\end{array}$ & $52.63 \pm 10.55$ & $80.26 \pm 15.99$ & $112.81 \pm 19.66$ & 45 & $\begin{array}{l}96 ; \\
90-100\end{array}$ & $54.35 \pm 13.98$ & $86.3 \pm 18.92$ & $129.53 \pm 27.4$ & $<0.001$ & 0.5 & 0.09 & 0.001 \\
\hline 20 & 40 & $\begin{array}{l}100 \\
99-100\end{array}$ & $55.83 \pm 12.46$ & $82.15 \pm 15.89$ & $116.78 \pm 18.47$ & 31 & $\begin{array}{l}99 \\
93-100\end{array}$ & $54.75 \pm 12.73$ & $88.75 \pm 19.15$ & $125.87 \pm 27.38$ & 0.003 & 0.73 & 0.11 & 0.12 \\
\hline 25 & 18 & $\begin{array}{l}100 ; \\
98.75-100\end{array}$ & $58.58 \pm 10.35$ & $85.88 \pm 15.53$ & $116.0 \pm 19.01$ & 13 & $\begin{array}{l}98 ; \\
91.5-99.5\end{array}$ & $54.15 \pm 7.88$ & $87.0 \pm 17.24$ & $122.71 \pm 28.43$ & 0.014 & 0.21 & 0.85 & 0.43 \\
\hline $\begin{array}{l}\text { After } \\
\text { proce- } \\
\text { dure }\end{array}$ & 53 & $\begin{array}{l}100 \\
98-100\end{array}$ & $50.12 \pm 10.01$ & $79.69 \pm 16.34$ & $118.56 \pm 17.47$ & 52 & $\begin{array}{l}100 ; \\
99-100\end{array}$ & $49.37 \pm 10.7$ & $83.0 \pm 17.19$ & $124.31 \pm 20.86$ & 0.59 & 0.71 & 0.31 & 0.14 \\
\hline
\end{tabular}

$\mathrm{SpO}_{2}$, pulse oximetry saturation; IQR, interquartile range; $\mathrm{PcCO}_{2}$, cutaneous carbon dioxide tension; LMA, laryngeal mask airway; NLMA, non-LMA; SBP, systolic blood pressure; HR, heart rate.

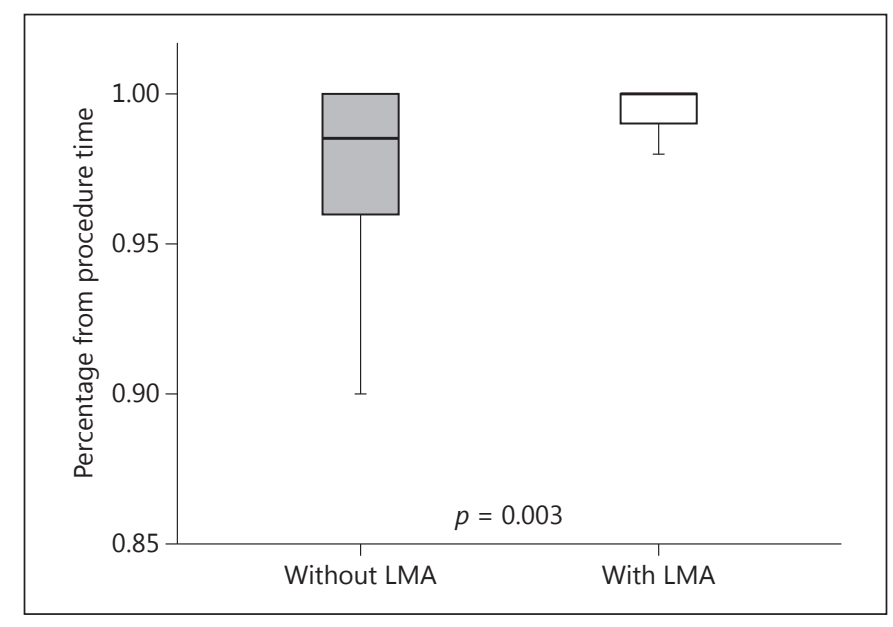

Fig. 1. Procedure time with $\mathrm{SpO}_{2}>88 \%$ represented by the percentage from procedure time.

Figure 1 display the rate of desaturation events and the percentage of procedure time with $\mathrm{SpO}_{2}>88 \%$.

\section{Secondary Outcomes}

The percentage of patients who had a rise of the $\mathrm{PcCO}_{2}$ level $>55 \mathrm{~mm} \mathrm{Hg}$ or a drop of the systolic blood pressure $<90 \mathrm{~mm} \mathrm{Hg}$ was similar (Table 2). The median $\mathrm{SpO}_{2}$ at 5 min intervals were significantly higher in the LMA group for procedure minutes $10-20(p<0.001, p<0.001$, and $p=0.003$ for procedure minutes 10,15 and 20 , respectively); the $\mathrm{SpO}_{2}$ level remained high beyond $20 \mathrm{~min}$, but the number of patients was not sufficient for statistical analysis, since procedure time was, in most cases $(71.2 \%), \leq 20$ min (Table 3, Fig. 2). Sedation required a significantly higher dose of propofol in the LMA group. The median propofol dosage was $200 \mathrm{mg}$ (IQR 165-300) in the LMA group and $120 \mathrm{mg}$ (IQR 70-200) in the NLMA group $(p<$ $0.001)$. There was no between-group difference in midazolam and fentanyl doses. The mean systolic blood pressure values were significantly lower in the LMA group in the first $15 \mathrm{~min}$ of the procedure $(p=0.02,<0.001$, and 0.001 for procedure minutes 5,10 , and 15 , respectively). The blood pressure values remained lower for the LMA group beyond $15 \mathrm{~min}$, but the difference did not reach statistical significance. There were no between-group differences in the mean $\mathrm{PCCO}_{2}$ level (Fig. 3) and heart rate during the procedure. Table 3 presents $\mathrm{SpO}_{2}, \mathrm{PcCO}_{2}$, heart rate, and systolic blood pressure monitoring during FFB.

\section{Adverse Events}

Overall 6 patients suffered an adverse event, 3 in the LMA group and 3 in the NLMA group. Adverse events in the LMA group were throat pain, lip trauma, and bronchospasm. In the NLMA group, 2 patients suffered from nose bleeding, and 1 patient suffered severe desaturation during the procedure and was intubated. None of the patients had severe arrhythmia during or after the procedure.

\section{Discussion}

The present study evaluated the efficacy and safety of LMA use for FFB. The results showed that LMA use is associated with a significantly higher $\mathrm{SpO}_{2}$ level throughout 


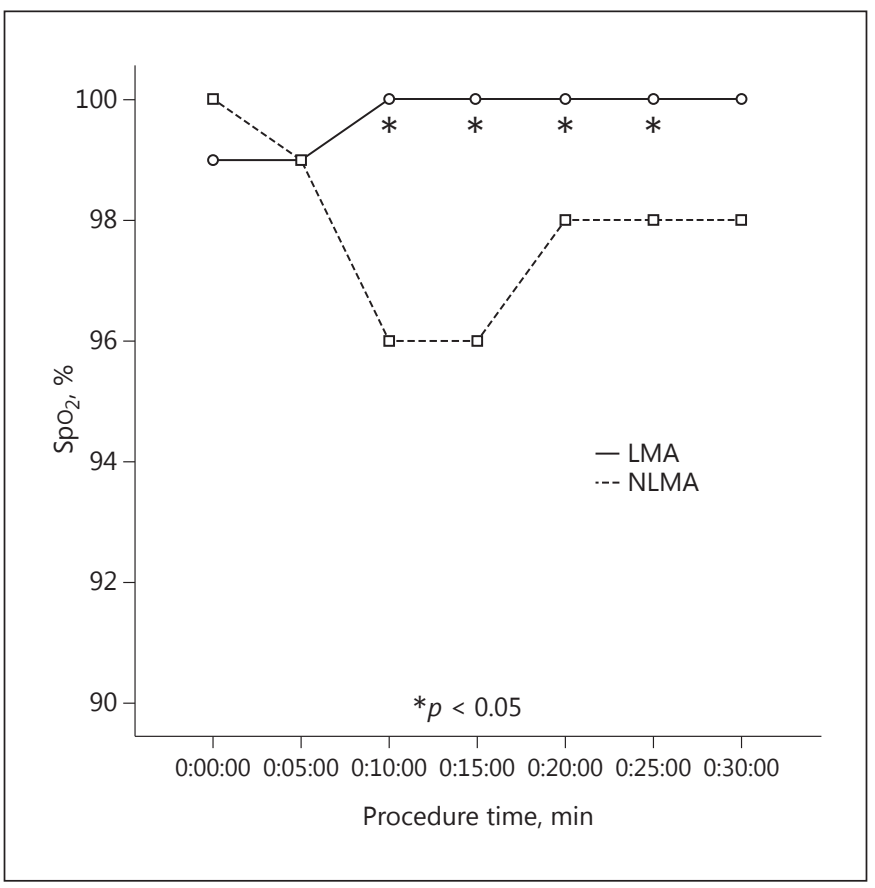

Fig. 2. Median $\mathrm{SpO}_{2}$ at 5-min intervals. Solid line, laryngeal mask airway; dashed line, nonlaryngeal mask airway.

the procedure and a significantly lower rate of desaturation $\left(\mathrm{SpO}_{2}<88 \%\right)$ events. These results are compatible with earlier studies, which evaluated the use of LMA in specific procedures [16-19]. Stable oxygen saturation for a prolonged time enables longer procedures, less interruption for oxygen enrichment, and ventilation and improved safety, especially for patients with comorbidities.

LMA insertion requires deeper sedation. Expected adverse events for higher doses of sedative drugs include oxygen desaturation, reduced systolic blood pressure, and severe hypotension (systolic blood pressure $<90 \mathrm{~mm}$ $\mathrm{Hg}$ ) [20-22]. Thus, LMA use is controversial in patients with multiple comorbidities. Our study did not exclude patients with comorbidities and was therefore eligible to assess the safety of LMA use in these patients. As expected, LMA use was associated with a significantly higher dose of propofol. In accordance, blood pressure monitoring during the procedure showed significantly lower systolic blood pressure values in the LMA group. Nevertheless, this difference did not result in a higher percentage of clinically significant hypotension. Moreover, even with a higher propofol dosage, no differences in the heart rate and $\mathrm{PcCO}_{2}$ values were noted. It is important to note that the patients in both groups were breathing spontaneously throughout the procedure and that the Ambu bag that

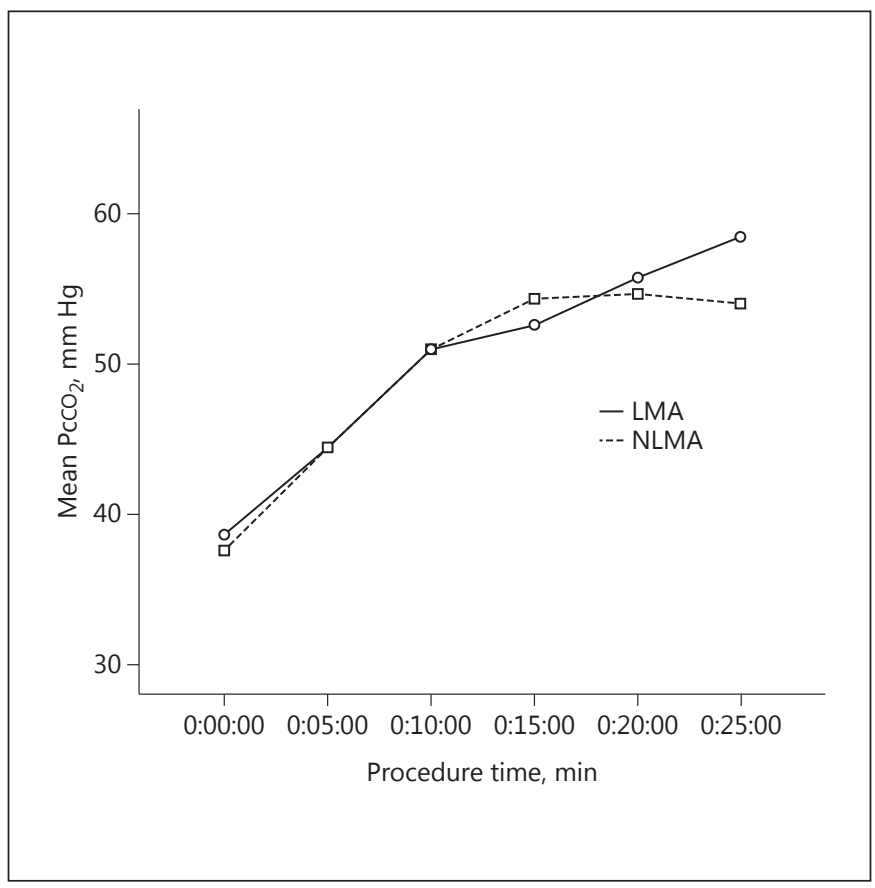

Fig. 3. Mean $\mathrm{PcCO}_{2}$ at 5-min intervals. Solid line, laryngeal mask airway; dashed line, nonlaryngeal mask airway.

was connected to the LMA was used only for additional ventilation during desaturation events. Overall 25 patients in the cohort had 2 comorbidities or more, and we did not see a higher frequency of adverse events in this group.

Our results show that LMA-assisted bronchoscopy enables higher levels of saturation even in prolonged procedures. Since the LMA is easy to insert and allows for a more convenient port of entry, it may be used even in simple procedures, but it will be most valuable in highrisk patients who would otherwise require protective intubation for the procedure and for long and complicated procedures such as endoscopic volume lung reduction, endobronchial ultrasound [23], and bronchial thermoplasty.

In conclusion, the use of LMA allows for better airway support, stable oxygen saturation, and a more convenient port of entry during FFB. These benefits should present as most useful in difficult cases and more prolonged procedures. In light of these benefits and the already known advantages of the laryngeal mask, more widespread use in the evolving field of interventional pulmonology is expected. 


\section{References}

1 Guidelines for fiberoptic bronchoscopy in adults. American Thoracic Society. Medical Section of the American Lung Association. Am Rev Respir Dis 1987;136:1066.

2 Du Rand IA, Blaikley J, Booton R, Chaudhuri N, Gupta V, Khalid S, Mandal S, Martin J, Mills J, Navani N, Rahman NM, Wrightson JM, Munavvar M; British Thoracic Society Bronchoscopy Guideline Group: Summary of the British Thoracic Society guideline for diagnostic flexible bronchoscopy in adults. Thorax 2013;68:786-787.

3 Milman N, Faurschou P, Grode G, Jørgensen A: Pulse oximetry during fibreoptic bronchoscopy in local anaesthesia: frequency of hypoxaemia and effect of oxygen supplementation. Respiration 1994;61:342-347.

4 Yserbyt J, De Maeyer N, Dooms C, Testelmans D, Muylle I, Bruyneel M, Ninane V: The feasibility of tracheal oxygen supplementation during flexible bronchoscopy. Respiration 2016;92:48-52.

5 Facciolongo N, Patelli M, Gasparini S, Lazzari Agli L, Salio M, Simonassi C, Del Prato B, Zanoni $\mathrm{P}$ : Incidence of complications in bronchoscopy. Multicentre prospective study of 20,986 bronchoscopies. Monaldi Arch Chest Dis 2009;71:8-14.

6 Jones AM, O'Driscoll R: Do all patients require supplemental oxygen during flexible bronchoscopy? Chest 2001;119:1906-1909.

7 Fang WF, Chen YC, Chung YH, Woon WT, Tseng CC, Chang HW, Lin MC: Predictors of oxygen desaturation in patients undergoing diagnostic bronchoscopy. Chang Gung Med J 2006;29:306-312.

8 Shinagawa N, Yamazaki K, Kinoshita I, Ogura S, Nishimura M: Susceptibility to oxygen desaturation during bronchoscopy in elderly patients with pulmonary fibrosis. Respiration 2006;73:90-94.

9 Brain AI: The laryngeal mask - a new concept in airway management. Br J Anaesth 1983;55: 801-805.

10 Springer DK, Jahr JS: The laryngeal mask airway. Safety, efficacy, and current use. Am J Anesthesiol 1995;22:65-69.

11 Pertusa V, Seller JM, Bellver J, Onrubia X, Barberá M: Fiberoptic bronchoscopy through a laryngeal mask (in Spanish). Rev Esp Anestesiol Reanim 1997;44:207-208.

12 Gottschall R: Fiber optic bronchoscopy with the laryngeal mask (in German). Anasthesiol Intensivmed Notfallmed Schmerzther 2004; 39:497-501.

13 García-Górriz M, Lucas-Talau M, Nuño-Sanz R, Trull-Ventura T, Montferrer-Estruch N, Miguel-Magro E: The laryngeal mask in fiber optic bronchoscopy in pediatric therapy (in Spanish). Rev Esp Anestesiol Reanim 1997; 44:208-209.

14 Goudra BG, Singh PM, Borle A, Farid N, Harris K: Anesthesia for advanced bronchoscopic procedures: state-of-the-art review. Lung 2015; 193:453-465.

15 Brimacombe J, Tucker P, Simons S: The laryngeal mask airway for awake diagnostic bronchoscopy. A retrospective study of 200 consecutive patients. Eur J Anaesthesiol 1995; 12:357-361.

16 Nussbaum E, Zagnoev M: Pediatric fiberoptic bronchoscopy with a laryngeal mask airway. Chest 2001;120:614-616.

17 Lohser J, Brodsky JB: Bronchial stenting through a ProSeal laryngeal mask airway. J Cardiothorac Vasc Anesth 2006;20:227-228.

18 Birmingham B, Mentzer SJ, Body SC: Laryngeal mask airway for therapeutic fiberoptic bronchoscopic procedures. J Cardiothorac Vasc Anesth 1996;10:519-520.

19 Madkour A, Elmansoury A, Sharkawy S: The efficacy of fiberoptic bronchoscopy through laryngeal mask airway in pediatric foreign body extraction. Egypt J Bronchol 2014;8:5763.

20 Grendelmeier P, Kurer G, Pflimlin E, Tamm M, Stolz D: Feasibility and safety of propofol sedation in flexible bronchoscopy. Swiss Med Wkly 2011;141:w13248.

21 Carmi U, Kramer MR, Zemtzov D, Rosengarten D, Fruchter O: Propofol safety in bronchoscopy: prospective randomized trial using transcutaneous carbon dioxide tension monitoring. Respiration 2011;82:515-521.

22 Matot I, Kramer MR: Sedation in outpatient bronchoscopy. Respir Med 2000;94:11451153.

23 Gershman E, Fruchter O, Benjamin F, Nader AR, Rosengarten D, Rusanov V, Fridel L, Kramer MR: Safety of cryo-transbronchial biopsy in diffuse lung diseases: analysis of three hundred cases. Respiration 2015;90:40-46. 